$\begin{array}{ll}\text { Lung } & \text { surface-active lipids } \\ \text { phospholipids } & \text { liver } \\ \text { choline } & \text { linoleic acid } \\ \text { fetus } & \text { palmitic acid }\end{array}$

\title{
Incorporation of Palmitate, Glucose and Choline into Lecithin by Fetal and Newborn Lamb Lung
}

\author{
N. ChIDA and F.H. AdAMs ${ }^{[37]}$ \\ Division of Cardiology, Department of Pediatrics, University of California \\ School of Medicine, Los Angeles, California, USA
}

\section{Extract}

Previous studies by us have shown that an increase in the lung surface-active phospholipids is closely related to fetal maturation. The present experiments were performed to determine the relation between fetal maturation and the rate of incorporation of several labelled precursors into phospholipids by lung slices from fetal and newborn lambs.

Lung and liver specimens were removed from seven fetal lambs of various gestational ages, nine newborn lambs ranging in age from 1 day to 6 months and from five of the mothers and one nonpregnant ewe. About $500 \mathrm{mg}$ of tissue, mixed with a radioactive precursor in Krebs Ringer Bicarbonate Buffer, was incubated at $38^{\circ}$ for three hours. The incorporation of ${ }^{14} \mathrm{C}$ from the various tagged precursors was determined by means of a radiochromatogram scanner after thin layer chromatography.

Results showed an increase in the rate of incorporation of ${ }^{14} \mathrm{C}$ labelled choline, palmitate and glucose into lung phospholipids, especially lecithin, as the fetus matured. Palmitate incorporation into lecithin was studied; after birth, it was found that the liver was less active than the lung until one month of age, but exceeded the lung in this function by three months after birth. These findings apparently reflect a difference in the development of the enzyme systems involved in phospholipid metabolism in both organs during maturation. From these studies, it is apparent that the lung of the maturing fetus is uniquely prepared for the synthesis of phospholipid, particularly of lecithin. The major significance of the higher rate of biosynthesis of lung lecithin in the fetus near term and newborn may be closely related to active synthesis of surfactant in the lung.

\section{Speculation}

It is concluded that the active biosynthesis of fatty acids or lecithin in the mature fetal and newborn periods is due to enzymatic changes associated with organ specific cell development. It seems possible that ineffective biosynthesis of lecithin or surface-active material in the immature fetus may form the basis for development of the respiratory distress syndrome. 


\section{Introduction}

Recent studies indicate that a substance with surface activity lines the internal surface of mammalian lungs [25]. The surface activity resides in the phospholipid moiety [20], chiefly the lecithin fraction [14, 24]. Fatty acids of the lecithin from lung extracts are highly saturated, palmitic acid being the major fatty acid [6, $15,24]$. The similarity of results of surface tension measurements from mammalian lung and synthetic dipalmitoyl lecithin suggests that this phospholipid may be the active constituent of lung surfactant.

The lungs of newborn infants dying of idiopathic respiratory distress syndrome (IRDS) usually show a reduction in surface activity $[2,3]$ and a reduction in the active phospholipid components [2]. Furthermore, almost all patients with IRDS are born prematurely $[26,27]$. Therefore, prematurity seems to be critical to the development of the syndrome.

Previous experiments by us have shown that an increase in the surface-active phospholipids of the lung is closely related to fetal maturation [7]. The present experiments were performed to determine the relation between fetal maturation and the rate of incorporation of several labelled precursors into phospholipids by fetal and newborn lamb lung slices.

\section{Materials and Methods}

Seven healthy fetal lambs at various gestational ages were delivered by cesarean section, using special precautions to maintain the placental circulation intact [1]. In each, the mother was sedated with nembutal given intravenously, placed on respiratory pump and ventilated with $100 \%$ oxygen, so as to maintain a normal maternal arterial $\mathrm{pH}$ and $\mathrm{PCO}_{2}$ As soon as the fetus was delivered onto a heated table, the trachea was ligated, a right thoracotomy was performed, and a portion of the right lower lobe of the lung and liver was removed. These specimens were immediately put into ice-cold Krebs Ringer Bicarbonate Buffer (KRBBuffer) at pH 7.4.

Lung and liver specimens were removed from nine newborn lambs ranging in age from 1 day to 6 months and from five of the mothers and one nonpregnant ewe. The lambs were sacrificed by injecting $2 \%$ xylocaine intracisternally. A thoracotomy was immediately performed, and a portion of the right lower lobe of the lung and the liver was removed and handled as in the case of fetal tissue.

Tissue slices were prepared in the cold room at $5^{\circ}$ using a Stadie-Riggs slicer. About $500 \mathrm{mg}$ of tissue, containing about $40 \mathrm{mg}$ of protein, was put into a flask with $50 \mu$ mole of $\mathrm{D}$-glucose, $10 \mu$ mole of sodium gluta- mate, a radioactive precursor and $\mathrm{KRB}-\mathrm{Buffer}$ to bring the final volume to $5 \mathrm{ml}$ [8]. Each flask was capped with a rubber top and prior to incubation was gassed with $5 \% \mathrm{CO}_{2}$ and $95 \% \mathrm{O}_{2}$ for twenty minutes. The incubation was carried out at $38^{\circ}$ for three hours and was terminated by placing in dry ice.

\section{Substrates}

As a precursor of phospholipids, palmitic acid- $1-{ }^{14} \mathrm{C}^{1}$ $0.425 \mu$ mole (specific activity $23.5 \mathrm{mc} / \mathrm{mmole}$ ), linoleic acid- $1-{ }^{14} \mathrm{C}^{2} \quad 1.0 \mu$ mole (specific activity $10.0 \mathrm{mc} /$ mmole), D-glucose- ${ }^{14} \mathrm{C}$ (U.L.) $0.43 \mu$ mole (specific activity $11.4 \mathrm{mc} / \mathrm{mmole}$ ), or choline-methyl- ${ }^{14} \mathrm{C}$ chloride $1.04 \mu$ mole (specific activity $4.8 \mathrm{mc} / \mathrm{mmole}$ ) were used. Palmitic acid- $1-{ }^{14} \mathrm{C}$ was added as an acid-albumin complex prepared according to Frllerup et al. [12]. Linoleic acid-albumin complex was prepared according to Elsbach [10]. Glucose- $-{ }^{14} \mathrm{C}$ or choline-methyl-14 $\mathrm{C}$ was used in $0.85 \% \mathrm{NaCl}$ solution.

\section{Determination of Protein}

Protein was determined according to the method of LowRY et al. [23] using bovine serum standards.

\section{Analysis of Lipids}

The medium and tissue slices were quantitatively transferred to a cup containing $25 \mathrm{ml}$ of degassed chloroform: methanol $(2: 1 \mathrm{v} / \mathrm{v})$ and were homogenized with a Virtis homogenizer. The extracts were filtered through Whatman No. 1 paper, and the residue was extracted three times with chloroform: methanol $(2: 1$ $\mathrm{v} / \mathrm{v})$. The combined extracts were washed three times according to FoLch et al. [13] and were then evaporated to dryness using a flash evaporator (Buchler Instruments, Model FE-2, Fort Lee, New Jersey).

The total phospholipids were separated from the neutral lipids and fatty acids on a silicic column according to BORGSTRÖM [4]. The water-soluble radioactive materials were quantitatively removed by this procedure. Thin layer chromatography (TLG) of neutral lipids and phospholipids was carried out according to SkIPSKr et al. $[28,29]$, except that silica gel H (E. Merck A.G., Darmstadt) was used instead of Camag D-O.

\section{Determination of Radioactivity}

The radioactivity of the total phospholipids and neutral lipids was determined by means of a Packard Liquid Scintillation Counter (Model 574), with a counting efficiency of $60.4 \%$. In order to determine the distribution of radioactivity in the phospholipid or neutral lipid fractions, preliminary experiments were performed to compare two methods, A and B.

1 New England Nuclear Corporation, Boston, Mass. 2 Volk Radiochemical Company, Burbank, Cal. 
Method A: After TLC, each fraction was extracted with chloroform: methanol $(1: 1 \mathrm{v} / \mathrm{v})$ as reported previous [7] with a recovery of $88-91 \%$. A Packard Liquid Scintillation Counter was used to determine the radioactivity of each fraction.

Method B: After TLC with $5 \times 20 \mathrm{~cm}$ plates, the radioactivity of each fraction was directly counted by means of a Packard Radiochromatogram Scanner (Model 7201) [8].

Both methods gave satisfactory results, but $B$ gave more constant results under the same conditions (thickness of plate, counting speed, collimator sensitivity etc.). Therefore, method B was used in the present experiment. After scanning, the curve was cut out and weighed to calculate the curve area and counting rate.

\section{Calibration of Radiochromatogram Scanner}

A known amount of palmitic acid-1-14 $\mathrm{C}$ was applied to the TLG plate. TLC was performed as described above. Standard samples were run alongside each sample. The plate was dried in the air and was analyzed for radioactivity on the Packard Radiochromatogram Scanner (Model 7201). (Efficiency $=\mathrm{cpm} / \mathrm{dpm} \times 100$ $=16.4 \%$.)

\section{Results}

Distribution of Radioactivity Incorporated into Phospholipid and Neutral Lipid Fractions

The incorporation of ${ }^{14} \mathrm{C}$ from the various ${ }^{14} \mathrm{C}$ tagged precursors (palmitic acid, linoleic acid, choline and glucose) was determined by means of a radiochromatogram scanner after TLC. The radiochromatograms of the phospholipids thus obtained are shown in figure 1. In figure 1, the top radiochromatogram shows the distribution of radioactivity incorporated from palmitate $-1{ }^{14} \mathrm{C}$ into the phospholipids by a mature fetal lung. The lower tracing shows the incorporation of palmitate into the phospholipids by the lung from the mother of the same fetus.

Fig. 2. Incorporation of palmitate- $1-{ }^{14} \mathrm{C}$ into neutral lipids of lung slices as a function of incubation time. The data are based on the average of duplicate determinations.

Abbreviations for this and future figures:

MG: monoglyceride

1,2 DG: 1,2 diglyceride

FFA: free fatty acid

CE: cholesterol ester

CF : free cholesterol

1,3 DG: 1,3 diglyceride

$\mathrm{TG}$ : triglyceride

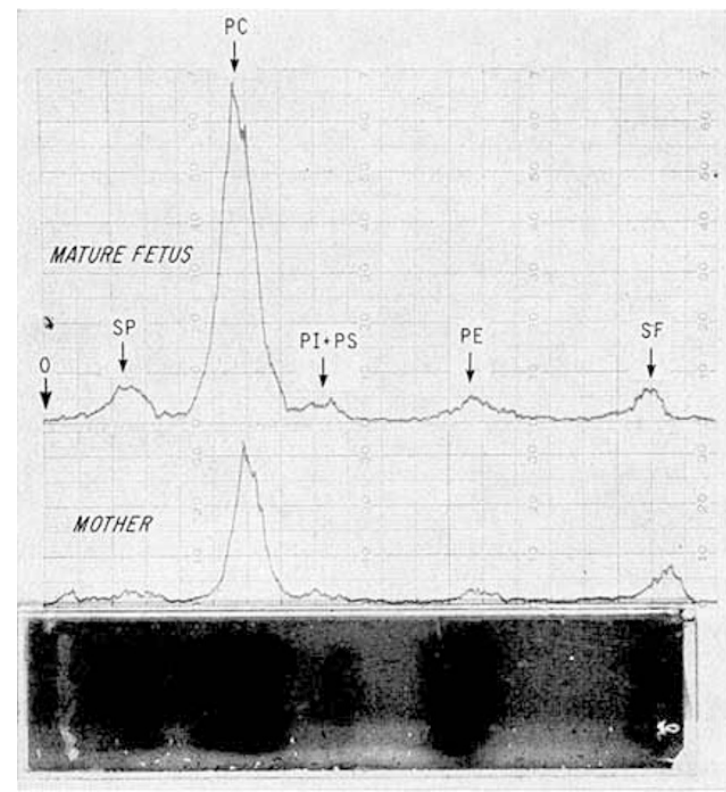

Fig. 1. Incorporation of palmitate- $1 .{ }^{14} \mathrm{C}$ into phospholipids. Lowest portion shows TLG separation of phospholipids. The top radiochromatogram shows the distribution of radioactivity of the corresponding phospholipids by the lung from a mature fetal lamb. The lower tracing shows the incorporation of palmitate into the phospholipids by the lung from the mother of the same fetus. Scanning was carried out under the same conditions in both cases. Abbreviations for this and future figures:

SP: sphingomyelin

PI: phosphatidylinositol

PS: phosphatidylserine

PG: lecithin

PE: phosphatidylethanolamine

$\mathrm{SF}$ : solvent front

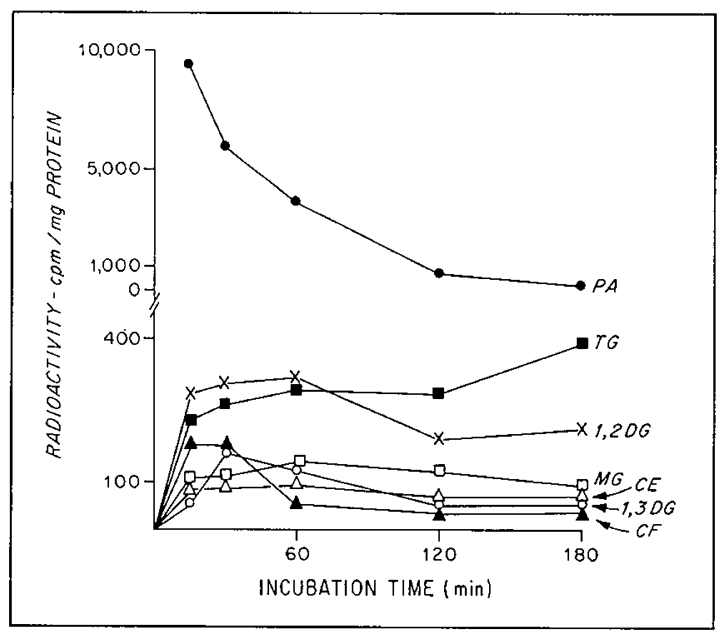


Incorporation of palmitate, glucose and choline into lecithin by fetal and newborn lamb lung

Table I. Incorporation of palmitic acid-1 $-{ }^{14} \mathrm{C}$ into lung phospholipids after 3 hours of incubation

\begin{tabular}{|c|c|c|c|c|c|c|c|}
\hline \multirow{2}{*}{$\begin{array}{l}\text { Animal } \\
\text { No. }\end{array}$} & \multirow[t]{2}{*}{ Age } & \multicolumn{6}{|c|}{ Phospholipids, CPM/mg protein } \\
\hline & & Total & SP & PG & $\mathrm{PI}+\mathrm{PS}$ & $\mathrm{PE}$ & $\mathrm{SF}$ \\
\hline $170 \mathrm{a}$ & $85^{1}$ & 2,962 & 206 & 1,517 & 275 & 344 & 620 \\
\hline $146 \mathrm{a}$ & $105^{1}$ & 2,045 & 56 & 955 & 119 & 77 & 837 \\
\hline $132 \mathrm{a}$ & $115^{1}$ & 1,199 & 99 & 195 & 33 & 47 & 826 \\
\hline $151 \mathrm{a}$ & $120^{1}$ & 895 & 一 & 212 & 22 & 44 & 617 \\
\hline $133 a$ & $125^{1}$ & 2,213 & 138 & 1,304 & 102 & 161 & 509 \\
\hline $164 a$ & $125^{1}$ & 3,246 & 318 & 2,331 & 155 & 238 & 205 \\
\hline $167 \mathrm{a}$ & $135^{1}$ & 4,633 & 364 & 3,469 & 219 & 254 & 328 \\
\hline $138 a$ & 1 day & 6,620 & 226 & 4,132 & 509 & 302 & 1,450 \\
\hline $161 \mathrm{a}$ & 3 days & 11,996 & 661 & 8,157 & 541 & 860 & 1,777 \\
\hline $163 a$ & 10 days & 25,802 & 1,138 & 15,556 & 3,794 & 3,834 & 1,478 \\
\hline 180 & 1 month & 7,975 & 468 & 5,622 & 211 & 234 & 1,440 \\
\hline 181 & 1 month & 6,782 & 127 & 4,882 & 403 & 276 & 1,093 \\
\hline 175 & 3 months & 4,221 & 161 & 3,062 & 122 & 182 & 693 \\
\hline 176 & 3 months & 4,223 & 489 & 2,736 & 163 & 141 & 693 \\
\hline 178 & 6 months & 3,487 & 189 & 1,998 & 134 & 104 & 1,061 \\
\hline 179 & 6 months & 4,784 & 283 & 2,883 & 240 & 138 & 1,240 \\
\hline 131 & adult & 4,495 & 188 & 1,588 & 148 & 138 & 2,433 \\
\hline 132 & adult & 3,817 & 147 & 751 & 101 & 82 & 2,736 \\
\hline 146 & adult & 2,738 & 164 & 1,151 & 138 & 147 & 1,138 \\
\hline 151 & adult & 4,889 & 116 & 2,649 & 237 & 207 & 1,680 \\
\hline 164 & adult & 2,268 & 109 & 744 & 81 & 84 & 169 \\
\hline 171 & adult (non preg.) & 4,847 & 125 & 2,957 & 268 & 250 & 1,248 \\
\hline
\end{tabular}

${ }^{1}$ Estimated fetal age based on body weight

SP: sphingomyelin; PG: phosphatidylcholine PI: phosphatidylinositol; PS: phosphatidylserine

$\mathrm{PE}$ : phosphatidylethanolamine; SF : solvent front

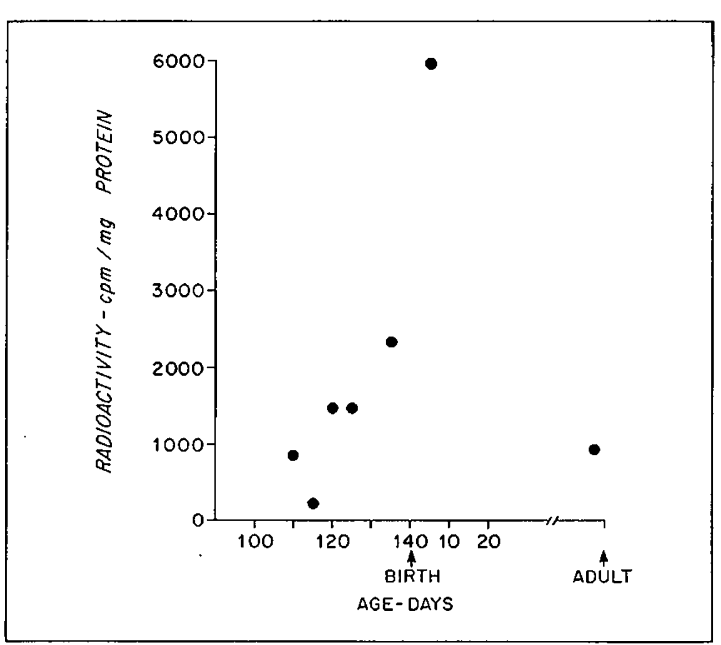

Fig.5. Influence of maturation on incorporation of choline methyl ${ }^{14} \mathrm{C}$ into lecithin of lung slices. The data are based on the average of duplicate determinations.

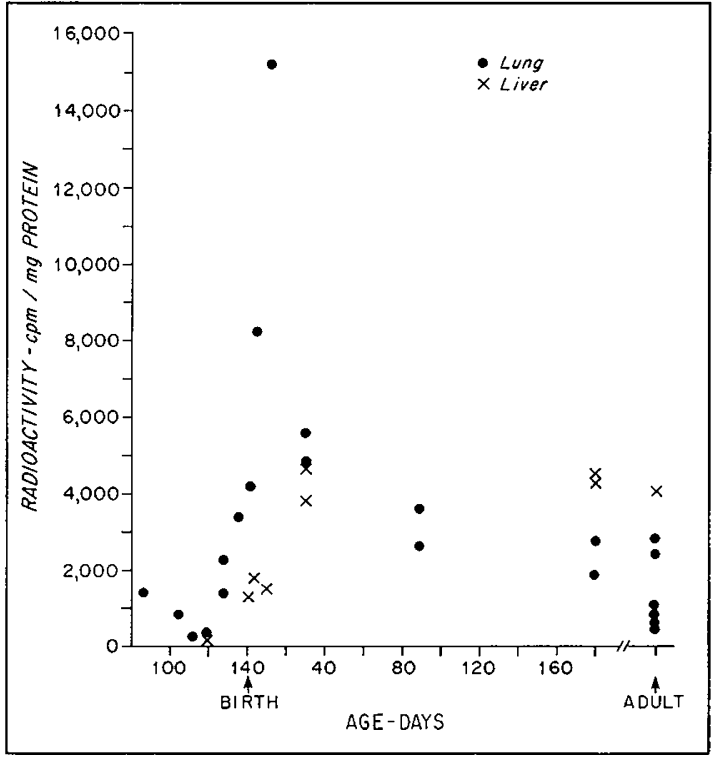

Fig.6. Influence of maturation on incorporation of palmitate- $1-{ }^{14} \mathrm{C}$ into lecithin of lung slices and liver slices. The data are based on the average of duplicate determinations. 
The chloroform fraction from the silicic acid column chromatography (nonphospholipid-lipid) was subjected to TLC followed by radiochromatography.

Incorporation of Palmitic Acid into Neutral Lipids

Figure 2 shows the time course of incorporation of palmitate- $1{ }^{14} \mathrm{C}$ into neutral lipids in the lung tissue from a mature fetus. For the first 60 minutes, 1,2 diglyceride and triglyceride showed a similar amount of radioactivity, but the former decreased after $120 \mathrm{~min}$ utes whereas the latter increased. Monoglyceride, free cholesterol, ester cholesterol and 1,3 diglyceride showed no significant radioactivity.

\section{Incorporation of Palmitic Acid into Phospholipids}

The time course of incorporation of palmitate- $1-{ }^{14} \mathrm{C}$ into the phospholipid fraction in the lung tissue from a mature fetus is illustrated in figure 3 . The incorporation of ${ }^{14} \mathrm{C}$ into lecithin was significant at 15 minutes when no other fraction yet contained noticeable radioactivity. The solvent front fraction (SF) contained some radioactivity, but far less than that of lecithin. It is noteworthy that phosphatidylethanolamine, which is thought to be converted through methylation into lecithin, was usually low in radioactivity throughout the incubation period.

Influence of Maturation on Incorporation of Various Precursors into Phospholipids

The incorporation of palmitic acid into phospholipids by lung slices was compared among immature and mature fetuses, newborns, 1-, 3- and 6-month-old lambs and female adult sheep. As is illustrated in table $\mathrm{I}$, the incorporation rate ( $\mathrm{cpm} / \mathrm{mg}$ protein) was low in the immature group, except for the youngest which had a relatively high rate. The rate increased toward term and remained high immediately after birth. The incorporation rate was decreased after one month of age. The incorporation of ${ }^{14} \mathrm{C}$ from glucose${ }^{14} \mathrm{C}$ (U.L.) into lecithin was also highest in the newborn animals as illustrated in figure 4.

No significant difference in the incorporation rate for linoleic acid-1 $-{ }^{14} \mathrm{C}$ was observed when comparing immature fetuses and an adult ewe as shown in table II. Choline methyl- ${ }^{14} \mathrm{C}$ was actively incorporated into lecithin, showing a tendency similar to palmitic acid. Newborn animals showed the highest radioactivity as seen in figure 5.

Incorporation of Palmitic Acid into Phospholipids of the Liver In contrast to the lung slices, the incorporation rate of palmitate into the phospholipids by liver slices began to increase after birth. The liver was less active than the lung before one month of age, but as illustrated in figure 6 and tables I and III, the liver showed a re-

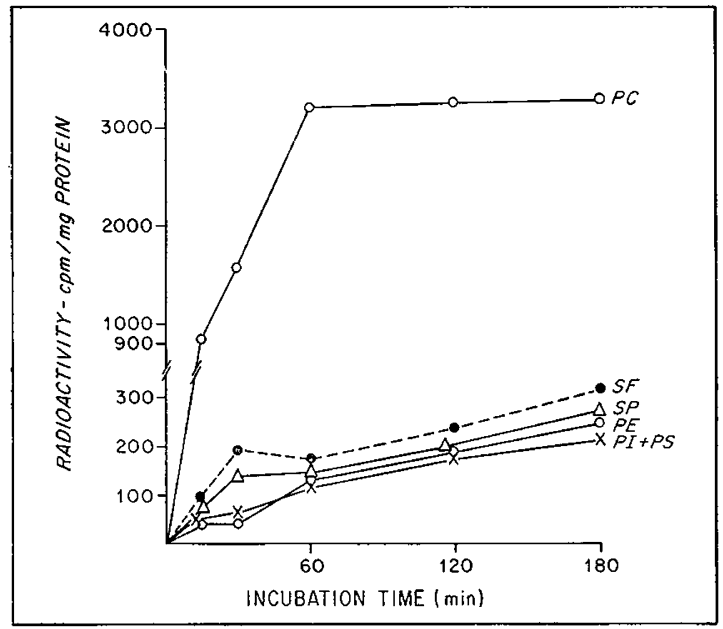

Fig. 3. Incorporation of palmitate- $1{ }^{14} \mathrm{C}$ into phospholipids of lung slices as a function of incubation time. The data are based on the average of duplicate determinations.

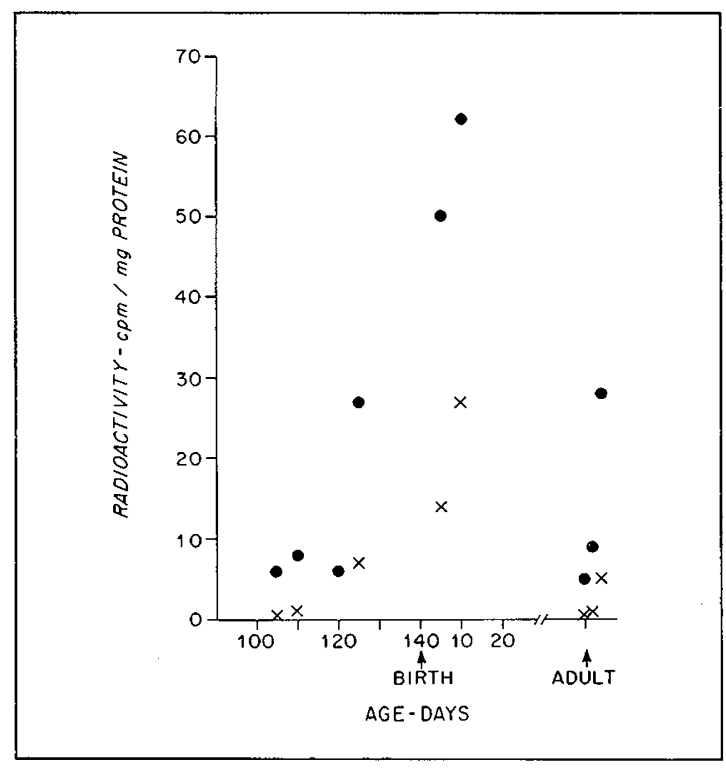

Fig.4. Influence of maturation on incorporation of Dglucose- ${ }^{14} \mathrm{C}$ (U.L.) into lecithin and phosphatidylethanolamine of lung slices.

- = lecithin

$x=$ phosphatidylethanolamine 
Incorporation of palmitate, glucose and choline into lecithin by fetal and newborn lamb lung

Table II. Incorporation of linoleic acid $-1-14 \mathrm{C}$ into lung phospholipids after 3 hours of incubation

\begin{tabular}{lllllrlr}
\hline $\begin{array}{l}\text { Animal } \\
\text { No. }\end{array}$ & Age & \multicolumn{5}{c}{ Phospholipids, CPM/mg protein } \\
\cline { 3 - 7 } & & Total & SP & PC & PI+PS & PE & \multicolumn{1}{c}{ SF } \\
\hline $15 \mathrm{I} \mathrm{a}$ & $120^{1}$ & 2,848 & 193 & 1,833 & 200 & 167 & 455 \\
$131 \mathrm{a}$ & $120^{1}$ & 3,766 & 225 & 1,545 & 72 & 127 & 1,797 \\
$164 \mathrm{a}$ & $125^{1}$ & 4,366 & 309 & 2,969 & 442 & 342 & 304 \\
$15 \mathrm{l}$ & adult & 6,275 & 211 & 1,685 & 156 & 136 & 4,087 \\
\hline
\end{tabular}

${ }^{1}$ Estimated fetal age based on body weight

For abbreviations, see table I

Table III. Incorporation of palmitic acid- $1{ }^{14} \mathrm{C}$ into liver phospholipids after 3 hours of incubation

\begin{tabular}{|c|c|c|c|c|c|c|c|}
\hline \multirow{2}{*}{$\begin{array}{l}\text { Animal } \\
\text { No. }\end{array}$} & \multirow[t]{2}{*}{ Age } & \multicolumn{6}{|c|}{ Phospholipids, CPM/mg protein } \\
\hline & & Total & SP & $\mathrm{PG}$ & $\mathrm{PI}+\mathrm{PS}$ & $\mathrm{PE}$ & $\mathrm{SF}$ \\
\hline $131 \mathrm{a}$ & $120^{1}$ & 516 & 82 & 239 & 45 & 21 & 130 \\
\hline 138 & 1 day & 2,819 & 155 & 1,380 & 217 & 168 & 899 \\
\hline 161 & 3 days & 2,861 & 39 & 1,798 & 73 & 80 & 872 \\
\hline 163 & 10 days & 2,372 & 163 & 1,506 & 69 & 199 & 437 \\
\hline 180 & 1 month & 5,412 & 350 & 3,835 & 77 & 109 & 1,041 \\
\hline 181 & 1 month & 7,035 & 312 & 4,711 & 509 & 411 & 1,091 \\
\hline 178 & 6 months & 6,293 & 624 & 4,374 & 166 & 125 & 957 \\
\hline 179 & 6 months & 6,708 & 831 & 4,442 & 128 & 106 & 1,109 \\
\hline 171 & adult (non preg.) & 5,699 & 419 & 4,194 & 222 & 226 & 638 \\
\hline
\end{tabular}

${ }^{1}$ Estimated fetal age based on body weight

For abbreviations, see table I

markable increase in incorporation rate after birth, exceeding the lung at three months after birth.

\section{Discussion}

The results obtained in this study showed an increase in the rate of incorporation of ${ }^{14} \mathrm{C}$ labelled choline, palmitate and glucose into lung phospholipids, especially lecithin, as the fetus matures. Similar results have been reported in the fetal lung of rats using ${ }^{32} \mathrm{P}$ [33], rabbits using CDP-ethanolamine [16], and lambs using acetate- $1-{ }^{14} \mathrm{C}[8]$.

Two pathways are known for the de novo synthesis of lecithin in various tissues: 1 . Preformed, free choline can be incorporated into lecithin via phosphoryl choline and cytidine diphosphate choline (CDP-choline), and 2. phosphatidylethanolamine can be converted to lecithin by stepwise methylation using the methyl groups from adenosyl methionine [5, 34]. This latter pathway also represents a mechanism for the de novo biosynthesis of choline. Furthermore, lecithin can be formed by acylation of lysolecithin by means of acyl CoA $[21,22]$.

Choline-methyl-14 $\mathrm{C}$ was actively incorporated into lecithin of mature fetal lung, indicating that the pathway becomes active as the fetus matures. However, in addition to the de novo synthesis of lecithin from choline, it has been reported that free choline incorporation into lecithin also takes place via an exchange reaction between free choline and preformed lecithin [9]. Therefore, the data of choline ${ }^{14} \mathrm{C}$ incorporation in this study probably represent the overall incorporation of choline into phospholipid via these pathways. The second pathway for the de novo synthesis of lecithin was not studied in the present investigation. Guuck et al. [16] recently reported that CDP-ethanolamine was actively incorporated into lecithin by developing fetal rabbit lung.

It is known that lung slices from adult animals catalyze esterification of fatty acids into phospholipid, chiefly lecithin [11]. Although the present study is not 
definitive regarding the lysolecithin acylating system in lecithin synthesis, marked incorporation of palmitate into lecithin was observed shortly after incubation and before incorporation into other intermediates such as $\mathrm{D}-\alpha, \beta$-diglyceride, phosphatidic acid or phosphatidylethanolamine. In this connection, WeBSTER [32] has recently shown the acylation of lysolecithin in the lung.

The selectivity in incorporation of fatty acids into lecithin of the fetal lung was not a subject of this study, and the amounts of labelled palmitate and linolate added to the incubation medium were not equimolar. Nevertheless, it should be noted that in spite of the greater amount of linolate than palmitate added to the medium, the incorporation rate of linolate into lecithin was usually lower than that of palmitate in animals of the same age groups. In addition, as reported previously, there was a preferential synthesis of fatty acids from acetate in the fetal lung, the palmitic acid being highly labelled with ${ }^{14} \mathrm{C}[8]$. Furthermore, it has been shown that lung lecithin contains predominantly palmitic acid [7, 15, 24]. It is therefore conceivable that the enzymes involved in lecithin synthesis may have a greater affinity for palmitate than other fatty acids.

The metabolism of glucose in phospholipid biosynthesis appears to be essential for providing acetate, L-alpha glycerophosphate and a source of reduced nicotinamide adenine dinucleotide phosphate. The latter is obtained from the hexosemonophosphate oxidative pathway of glucose degradation, which is active in the lung tissue of fetal animals [30].

The results obtained with uniformly labelled glucose showed that the rate of overall incorporation of glucose into lecithin of the lung was greater in relatively mature fetuses than the immature ones and adults. WEINHOLD and VILLEE [33] reported that the overall pattern of ${ }^{32} \mathrm{P}$ incorporation into the phospholipid was different in liver and lung during maturation, i.e., the liver labelling declined before birth and increased sharply after birth, whereas in the lung, the radioactivity increased several fold prior to birth. A similar pattern of palmitate incorporation into lecithin was obtained in our study, but after birth, it was found that liver was less active than the lung before one month of age, but exceeded the lung three months after birth. These findings apparently reflect a difference in the development of the enzyme systems involved in phospholipid metabolism in both organs during maturation.

From these studies and others $[8,11,16,33]$, it is apparent that the lung of the maturing fetus is uniquely oriented for the synthesis of phospholipid, particularly of lecithin. The major significance of the high rate of biosynthesis of lecithin in the lung of the fetus near term and in the newborn may be closely related to active synthesis of surfactant in the lung. Our previous study showed a close relation between the appearance of surface activity and the increase in saturated lecithin in the saline extract of the fetal lung with maturation [7]. Furthermore, in a close correlation with the appearance of surface activity in the fetal lung, the appearance of and an increase in the number of the inclusion bodies in the alveolar cells which are considered to be the source of surfactant are reported to take place [19].

It seems likely that an inadequate amount of active surfactant in immaturity may be due to inactive synthesis of lecithin, probably because of inadequate development of enzyme systems involved in phospholipid metabolism.

\section{Summary}

A study was made of the biosynthesis of lecithin from various ${ }^{14} \mathrm{C}$ labelled precursors in lung tissues in vitro using immature and mature fetal lambs, newborn lambs ( $1-10$ days), lambs of 1,3 and 6 months of age and mother sheep. The incorporation of ${ }^{14} \mathrm{C}$ from palmitate-1 $1{ }^{14} \mathrm{C}$ was generally low in the immature fetuses, but was high in the mature fetuses, and the highest values were obtained in the newborn period. Cholinemethyl- ${ }^{14} \mathrm{C}$ was incorporated most effectively into lecithin by the newborn and mature fetal lungs. Glucose- ${ }^{14} \mathrm{C}$ was not an effective precursor for lecithin. In contrast, in the liver, an increase in palmitate incorporation into lecithin was observed after birth and it exceeded the lung at 3 months of age. The possible relation between these biochemical findings and pulmonary surfactant is discussed with special reference to maturation.

\section{References and Notes}

1. Adams, F.H.; Moss, A.J. and Fagan, L.: The tracheal fluid in the fetal lamb. Biol. Neonat. 5: 151 (1963).

2. Adams, F.H.; Fujiwara, T.; Emmanouilides, G. and Scudder, A.: Surface properties and lipids from lungs of infants with hyaline membrane disease. J. Pediat. 66: 357 (1965).

3. Avery, M.E. and MEAD, J.: Surface properties in relation to atelectasis and hyaline membrane disease. Amer.J. Dis. Child. 97: 517 (1959).

4. Borgström, B.: Investigation on lipid separation methods. Separation of phospholipids from neutral fat and fatty acids. Acta physiol.scand. 25: 101 (1952).

5. Bremer, J.; Figard, P.H. and Greenberg, D. M. : The biosynthesis of choline and its relation to phospholipid metabolism. Biochim. biophys. Acta 43: 477 (1960).

6. Brown, E.S.: Isolation and assay of dipalmityl 
Incoporation of palmitate, glucose and choline into lecithin by fetal and newborn lamb lung

lecithin in lung extracts. Amer.J. Physiol. 207: 402 (1964).

7. Chida, N.; Adams, F.H.; Nozaki, M. and NoRMAN, A.: Changes in lamb-lung lipids during gestation. Proc. Soc. exp. Biol. (N.Y.) 122: 60 (1966).

8. CHIDA, N. and ADAms, F.H.: Incorporation of acetate into fatty acids and lecithin by lung slices from fetal and newborn lambs. J.Lipid Res. 8: 335 (1967).

9. Drrs, R.R. and Hübscher, G.: Metabolism of phospholipids. III. The effect of calcium ions on the incorporation of labeled choline into rat-liver microsomes. Biochim. biophys. Acta 46: 505 (1961).

10. Elsbach, P.: Incorporation of (1- $\left.\mathrm{C}^{14}\right)$ linoleic acid into lipids of polymorphonuclear leukocytes. Biochim. biophys. Acta 70: 157 (1963).

11. Felts, J.M.: Biochemistry of the lung. Health Phys. 10: 973 (1964).

12. Fillerup, D. L.; Migliore, J. G. and Mead, J.F.: The uptake of lipoproteins by ascites tumor cells. J. biol. Ghem. 233: 98 (1958).

13. Folch, J.; Ascoli, I.; Lee, M.; Meath, J.A. and LEBARon, F.N.: Preparation of lipid extract from brain tissue. J.biol. Chem. 191: 833 (1951).

14. Fujiwara, T. and Adams, F.H.: Isolation and assay of surface-active phospholipid components from lung extracts by thin-layer chromatography. Tôhoku J. exp. Med. 84: 46 (1964).

15. Fujiwara, T.; Hirono, H. and Arakawa, T.: Chemical identification of surface active material isolated from calf lung. Tôhoku J.exp. Med. 85: 33 (1965).

16. Gluck, L. and Saribney, M. : Synthesis of phospholipids in the lung of the developing rabbit fetus. Physiologist 8: 174 (1965).

17. Kennedy, E.P. and Weiss, S.B.: The function of cytidine coenzymes in the prosynthesis of phospholipids. J. biol. Chem. 222: 193 (1956).

18. Kennedy, E.P.: Biosynthesis of complex lipids. Fed.Proc. 20: 934 (1961).

19. Kikkawa, Y.; Мотoyama, E.K. and Cook, C.D.: The ultrastructure of the lungs of lambs. Amer.J.Path. 47: 877 (1965).

20. Klaus, M.H.; Glements, J.A. and Havel, R.J.: Composition of surface-active material isolated from beef lung. Proc.nat. Acad.Sci. (Wash.) 47: 1858 (1961).

22. LANDS, W.E.M.: Metabolism of glycerolipids. II. The enzymatic acylation of lysolecithin. J. biol. Chem. 235: 2233 (1960).

22. LANDS, W.E. M. and MERKL, I.: III. Reactivity of various acyl esters of coenzyme A with $\alpha^{\prime}$-acylglycerophosphorylcholine, and positional specificities in lecithin synthesis. J. biol. Chem. 238: 898 (1963).
23. Lowry, D.H.; Rosebrough, N.J.; FArR, A.L. and RANDALL, R.J.: Protein measurement with the Folin phenol reagent. J. biol. Chem. 193: 265 (1951).

24. Morgan, T.E.; Frnlex, T.N. and Fialkow, H.: Comparison of the composition and surface activity of 'alveolar' and whole lung lipids in the dog. Biochim. biophys. Acta 106: 403 (1965).

25. Pattle, R.E.: Surface lining of lung alveoli. Physiol. Rev. 45: 48 (1965).

26. Silverman, W.A. and Silverman, R.H.: Incidence of hyaline membrane in premature infants. Lancet ii: 588 (1958).

27. Sivanesan, S.: Neonatal pulmonary pathology in Singapore. J.Pediat. 59: 600 (1961).

28. Skipski, V.P.; Peterson, R.F. and Barclay, M. : Quantitative analysis of phospholipids by thinlayer chromatography. Biochem. J. 90: 374 (1964).

29. Skipski, V.P.; Smolowe, A. F.; Sullivan, R. C. and BARclay, M.: Separation of lipid classes by thin-layer chromatography. Biochim.biophys. Acta 106: 386 (1965).

30. Sorokin, S.: A study of development in organ cultures of mammalian lungs. Dev. Biol. 3: 60 (1961).

31. Stein, Y.; Stein, O. and Shapiro, B.: Enzymatic pathways of glyceride and phospholipid synthesis in aortic homogenates. Biochim. biophys. Acta 70: 33 (1963).

32. Webster, C.R.: The acylation of lysophosphatides with long-chain fatty acids by rat brain and other tissues. Biochim. biophys. Acta 38: 512 (1965).

33. Weinhold, P.A. and Villee, G.A.: Phospholipid metabolism in the liver and lungs of rats during development. Biochim. biophys. Acta 106: 540 (1965).

34. Wruson, J.D.; Gibson, K. D. and Udenfriend, S.: Studies on the precursors of the methyl groups of choline in the rat liver. J.biol. Chem. 235: 3213 (1960).

35. The authors are indebted to Prof. James F. Mead of the Laboratory of Nuclear Medicine and Radiation Biology, UCLA, for advice and help, including use of his equipment in the performance of these studies. We are also indebted to MARy MontgoMERy, Robert Eberhardt, Anne Norman and SARI Sipos for technical assistance. Thanks are also due to Dr. V.P. Skipski of Sloan-Kettering Institute for Gancer. Research and Mrs. D.L. Fillerup of UCLA for their technical advice in the performance of thin-layer chromatography.

36. Supported by grants from the USPHS.

37. Adams, F.H., M.D., Professor, Department of Pediatrics, University of California School of Medicine, Los Angeles, Cal. 90024 (USA). 